\title{
Funcionalidades das praças e parques públicos do estado de Sergipe como espaços públicos para políticas de promoção de saúde e lazer
}

\author{
Functionalities of squares and public parks in the state of Sergipe as public spaces for health and
} leisure promotion policies

Funcionalidades de la plaza y los parques públicos del estado de Sergipe como espacios públicos para las políticas de promoción de la salud y el ócio

\author{
Ailton Fernando Santana de Oliveira \\ ORCID: https://orcid.org/0000-0003-2894-3556 \\ Universidade Federal de Sergipe, Brasil \\ E-mail: ailtonufs@gmail.com \\ José Robson dos Santos \\ ORCID: https://orcid.org/0000-0001-5064-7644 \\ Secretaria Municipal de Educação de Aracaju, Brasil \\ E-mail: robsondede54@gmail.com \\ Tamires Nunes dos Santos \\ ORCID: https://orcid.org/0000-0001-9433-0008 \\ Universidade Federal de Sergipe, Brasil \\ E-mail: tamiresnunesds@gmail.com \\ Marcelo de Castro Haiachi \\ ORCID: https://orcid.org/0000-0002-9361-9018 \\ Universidade Federal de Sergipe, Brasil \\ E-mail: haiachi@academico.ufs.br
}

\begin{abstract}
Resumo
O uso do espaço urbano, a construção e animação dos equipamentos de atividades físicas de esporte e lazer constituem eixo fundamental de uma política de saúde e de lazer esportivo. Sendo assim, o acesso aos espaços públicos é de extrema importância para exercer a cidadania dos usuários, promovendo a vida social, qualidade de vida e bem estar. Com isso, o trabalho buscou identificar e mapear espaços públicos existentes nas cidades sergipanas, e a partir dessa identificação apontar os limites e superações para democratização do acesso a esses espaços e orientação à população, dessa forma, contribuir para tomada de decisão dos gestores públicos no combate ao sedentarismo e na elevação da cultura esportiva da população. O estudo utiliza uma abordagem qualitativa, realizando a coleta de dados através de uma pesquisa de campo, aplicando questionário semiestruturado e diário de campo em nove cidades Sergipanas. Poucas praças pesquisadas possuem módulo policial, médios e fortes rumores de uso de drogas, álcool e assaltos evidenciado, a maioria desses locais possui algum tipo de estrutura danificada, inutilizada ou pichada e poucos projetos de atividades físico/esportivas de iniciativa do poder público. Aspectos econômicos e de falta de tempo, estudo, cuidados com a casa, fazem com que muitas pessoas não tenham uma rotina de atividade física adequada. Mas, percebe-se que a falta de políticas públicas de orientação em atividade física, dificultam a massificação prática para a amostra em questão.
\end{abstract}

Palavras-chave: Qualidade espacial; Atividade física; Políticas públicas.

\begin{abstract}
The use of urban space, the construction and animation of equipment for physical activities for sport and leisure constitute a fundamental axis of a health and sports leisure policy. Therefore, access to public spaces is extremely important to exercise users' citizenship, promoting social life, quality of life and well-being. With this, the work sought to identify and map existing public spaces in Sergipe cities, and from this identification point out the limits and overcomings for the democratization of access to these spaces and guidance to the population, thus contributing to the decision-making of public managers in the combating sedentary lifestyles and raising the population's sports culture. The study uses a qualitative approach, performing data collection through field research, applying a semi-structured questionnaire and field diary in nine cities in Sergipe. Few surveyed squares have a police module, medium and strong rumors of evidenced use of drugs, alcohol and robberies, most of these places have some type of damaged, unused or graffiti structure and few projects of physical/sports activities initiated by the public authorities. Economic aspects and lack of time, study, housekeeping, make many people not have an adequate physical activity routine. But,
\end{abstract}


it is clear that the lack of public policies for guidance in physical activity, hinder the practical massification for the sample in question.

Keywords: Spatial quality; Physical activity; Public policy.

\section{Resumen}

El uso del espacio urbano, la construcción y animación de equipamientos para actividades físicas deportivas y de ocio constituyen un eje fundamental de una política de salud y ocio deportivo. Por tanto, el acceso a los espacios públicos es de suma importancia para el ejercicio de la ciudadanía de los usuarios, promoviendo la vida social, la calidad de vida y el bienestar. Con ello, el trabajo buscó identificar y mapear los espacios públicos existentes en las ciudades de Sergipe, y a partir de esta identificación señalar los límites y superaciones para democratizar el acceso a estos espacios y orientar a la población, contribuyendo así a la toma de decisiones de los gestores públicos en la lucha contra el sedentarismo y el fomento de la cultura deportiva de la población. El estudio utiliza un enfoque cualitativo, realizando la recolección de datos a través de la investigación de campo, aplicando un cuestionario semiestructurado y un diario de campo en nueve ciudades de Sergipe. Pocas plazas encuestadas cuentan con módulo policial, rumores medianos y fuertes de evidenciado uso de drogas, alcohol y robos, la mayoría de estos lugares tienen algún tipo de estructura dañada, sin uso o grafiti y pocos proyectos de actividades físico-deportivas iniciadas por las autoridades públicas. Aspectos económicos y falta de tiempo, estudio, limpieza, hacen que muchas personas no tengan una adecuada rutina de actividad física. Pero, es claro que la falta de políticas públicas de orientación en la actividad física, dificultan la masificación práctica de la muestra en cuestión.

Palabras clave: Calidad espacial; Actividad física; Políticas públicas.

\section{Introdução}

O presente estudo insere-se no bojo de estudos que visam diagnosticar ações de atividades físicas e esportivas em praças e parques públicos, a partir das práticas, dos praticantes, equipamentos e instalações. Nesse sentido, o objetivo desta pesquisa é identificar e mapear espaços públicos existentes nas cidades sergipanas, e a partir dessa identificação apontar os limites e superações para democratização do acesso a esses espaços bem como a melhoria do atendimento e orientação à população, dessa forma, contribuir para tomada de decisão dos gestores públicos no combate ao sedentarismo e na elevação da cultura esportiva da população.

O termo atividade física é definido com a forma básica do movimentar-se, como por exemplo no âmbito das atividades diárias. $\mathrm{O}$ esporte em contrapartida seria uma forma mais especial de movimentar-se. Portanto atividade física e esporte não podem ser na realidade separados, pois o esporte é uma atividade física caracterizada por uma modalidade esportiva específica e assim por uma variedade infinita de formas. Todo tipo de esporte tem o seu repertório típico de movimentos e seu perfil característico de exigências e, com isso, o seu efeito especial (Weineck, 2003). Já definição, "Exercício Físico é toda Atividade Física planejada, estruturada e repetitiva que tem por objetivo a melhoria e a manutenção de um ou mais componentes da aptidão física (Caspersen et al, 1985). Como exemplo, podemos citar uma caminhada de uma hora sem parar e com ritmo constante".

As atividades físicas esportivas e de lazer estão nos anseios de uma sociedade democrática, que compreende que sua vida é plena de direitos como: alimentação, saúde, educação, bem como viver com dignidade, de usufruir das emoções e prazeres de bens culturais produzidos historicamente pelos homens.

$\mathrm{O}$ uso do espaço urbano, a construção e animação dos equipamentos de atividades físicas de esporte e lazer constituem eixo fundamental de uma política de saúde e de lazer esportivo, no campo dos interesses físico-esportivos, assim como de qualquer dos seus conteúdos culturais (Barbuy, 1980; Marcellino, 2002c; Wilheim, 1976) e alguns estudos já mostram que o nível de atividade física dos adolescentes é baixo e algumas variáveis como segurança dos espaços públicos se associam com essa prática (Dias, 2015).

Sendo assim, o acesso aos espaços públicos é de extrema importância para exercer a cidadania dos usuários, promovendo a vida social, qualidade de vida e bem estar de todos que frequentam o ambiente (Silva, Silva, \& Sampaio, 2018). Portanto, a democratização do acesso a práticas de atividades físicas, sejam elas visando o rendimento, estética, saúde ou lazer, 
exige políticas públicas para além do que historicamente são implementadas, exigisse estudos sérios, diagnósticos, acompanhamento e avaliação do que se tem e do que se precisa, ou seja, precisa conhecer o grau de desenvolvimento dessas práticas, da legislação, financiamento e das suas instalações existentes.

Nesse sentido, as praças e parques, objetivo aqui em estudo, assumem um papel importante como local dessas práticas de atividade física, de esporte e lazer. Diante de problemas da atualidade que passam pela destruição ambiental e exploração imobiliária, bem como, os reduzidos espaços e instalações esportivas nas cidades. Portanto, passa a ser relevante um estudo que consiga identificar onde existem esses espaços, quando são, como são utilizados, por quem são utilizados, que ações os poderes públicos estão realizando, entre outras necessidades.

Com isso, uma praça pode ser definida como espaço aberto livre de edificações (Ecker, 2020; Viero \& Filho, 2009) e, no Brasil essa ideia está firmemente associada à presença de jardins e destinada ao trânsito exclusivo de pedestres. Originalmente associada aos pátios das igrejas, com a função de reunir as pessoas para as atividades religiosas ou não, hoje tem sua função principal voltada para o lazer da população.

Segundo Azevedo (2001), (...) as políticas públicas são definidas, implementadas, reformuladas ou desativadas com base na memória da sociedade ou do Estado em que têm lugar e por isso guardam estreita relação com as representações sociais que cada sociedade desenvolve sobre si própria. Ou seja, a partir de questões socialmente problematizadas, surgem políticas públicas para determinado setor, há um "reconhecimento" por parte do Estado desta necessidade/problema, e a política pública específica do setor virá para "suprir" os anseios de determinada representação social.

Como nos afirma Bonetti (2006), políticas públicas são frutos da dinâmica do jogo de forças que se estabelecem no âmbito das relações de poder, relações essas constituídas pelos grupos econômicos e políticos, classes sociais e demais organizações da sociedade. E para Gomes (2014), a população tem que participar no processo de produção dos espaços urbanos, pois, pode resultar em políticas públicas menos excludentes, assegurando um processo participativo mais democrático e fortalecendo a cidadania.

Marcellino (1998), coloca que a admissão da importância do lazer na vida moderna significa considerá-lo um tempo privilegiado para a vivência de valores que contribuam para mudanças de ordem moral e cultural, tais mudanças são necessárias para a implantação de uma nova ordem social. Para efeito de nosso estudo iremos delimitar o lazer na perspectiva esportiva e recreativa mais fácil de captar seu movimento nas praças e parques, pois, Sergipe também carece de sistematização das informações esportivas e de atividades físicas com um todo (Oliveira, 2019).

Dentro desse contexto, questiona-se: As políticas públicas referentes ao esporte e lazer estão sendo postas em prática em Sergipe? Em qual região ou cidades as praças estão sendo melhor utilizadas? Qual o público que mais utiliza essa infraestrutura? Há realmente infraestrutura?

Nesse sentido, um estudo que identifique a realidade existente, o potencial e a dificuldade que a população enfrenta para a realização de atividades físicas, esportivas e de lazer, entendendo o alto número de sedentarismo existente e os danos que ele provoca a saúde da população, torna-se fundamental, informação relevante para a tomada de decisão dos gestores.

\section{Procedimentos Metodológicos}

Enquanto base teórica explicativa, utilizou-se a teoria do conhecimento, que possibilitará compreender o movimento do real concreto (prática social) na sua totalidade com múltiplas relações, articulações, nexos e determinações, entendendo a ação humana como uma construção histórica, desenvolvendo instrumentos do pensamento, leis e categorias para a apreensão da realidade (Kosik, 2002; Cheptulin, 2004). 
Busca aprender a prática social empírica dos indivíduos em sociedade (nos grupos e classes sociais), e realizar a crítica das ideologias, isto é, do imbricamento do sujeito e do objeto, ambos históricos e comprometidos com os interesses e as lutas sociais de seu tempo. Assim, a visão dialética privilegia entender: a) contradição e o conflito predominando sobre a harmonia e o consenso; b) o fenômeno da transição, da mudança, do vir-a-ser sobre a estabilidade; c) o movimento histórico; d) a totalidade e a unidade dos contrários (Minayo, 2004; p.86 apud Demo, 1985; p.86 - 100).

Com o objetivo de alcançar esse movimento, propomos os seguintes caminhos para a pesquisa.

\subsection{Natureza da pesquisa}

$\mathrm{O}$ presente estudo, devido à caracterização do problema que trata de aspectos no âmbito do esporte, com especificidade do diagnóstico, sendo de natureza eminentemente social, utilizará uma abordagem qualitativa, no qual o sujeitopesquisador será parte integrante do processo de construção do conhecimento e da interpretação dos fenômenos (Kosik, 2002, p. 40), atribuindo-lhes significados.

\subsection{Instrumento de coleta dos dados}

A coleta de dados foi realizada através de uma pesquisa de campo, por meio de:

a) Aplicação de questionário semiestruturado aos sujeitos envolvidos, com conteúdo detalhadamente limitado, convalidado e validado, por especialistas;

b) Aplicação do questionário baseado no SOPARC - Sistem for Observing Play and Recreation in Comunities, com adaptações para a realidade de Sergipe;

c) Diário de campo, contendo observações pertinentes e captadas pelo pesquisador.

Cabe salientar que o instrumento de coleta de dados foi referenciado com base no SOPARC, que passou por avaliação de três especialistas e debatido em um seminário específico para sua aprovação final. Esse questionário contém questões referentes à estrutura e aos usuários. Após aprovação do documento final, foi realizado um estudo piloto, em um dos parques da cidade. Após análise dos dados do piloto e pequenas correções, o questionário foi aprovado para operacionalização da coleta.

\subsection{Sujeitos da Pesquisa}

Com relação aos espaços que serão pesquisados, por não haver condições de estabelecer estratos, já que cada espaço tem suas singularidades, bem como, os sujeitos envolvidos, e entendo que o resultado deverá apontar alternativas de políticas de esporte e lazer em cada município pesquisado. A pesquisa optou por investigar duas praças em cada município, com exceção de Aracaju (capital do estado), que foi dividida em oito regiões e em cada uma delas foram pesquisados duas praças e três parques. Esse recorte levou em consideração que após os estudos, será oferecida alternativas aos gestores para tomada de decisão de forma viável e dentro da realidade de cada município.

Com relação às entrevistas aplicadas aos usuários das praças pesquisadas, foi determinado um total de quarenta entrevistas por praça e parques, assim divididas: crianças, adolescentes, jovens e idosos, de ambos os sexos, de acordo com a interpretação etária do Instituto Brasileiro de Geografia e Estatística (IBGE) (Oliveira et al., 2016), sendo 10 entrevistas para cada grupo. Esse número de entrevista estabelecido foi aleatório, apenas para que possibilitasse entendermos um pouco a representatividade e a importância do espaço pelo usuário.

Para definição das cidades que foram pesquisadas utilizamos a divisão territorial realizada pelo governo do estado de Sergipe em parceria com a Universidade Federal de Sergipe intitulado: Estado de Sergipe: Uma proposta de 
territorialização para o planejamento (Teixeira et al., 2011). Nesse estudo, o Estado de Sergipe passa a ser dividido em 08 (oito) territórios.

Para definição desses territórios, os pesquisadores basearam-se no conceito de território proposto pelo Ministério do Desenvolvimento Agrário (2004), assim definido:

É um espaço físico, geograficamente definido, geralmente contínuo, compreendendo a cidade e o campo, caracterizado por critérios multidimensionais - tais como o ambiente, a economia, a sociedade, a cultura, a política e as instituições - e uma população com grupos sociais relativamente distintos que se relacionam interna $\mathrm{e}$ externamente por meio de processos específicos, onde se pode distinguir um ou mais elementos que indicam identidade e coesão social, cultural e territorial. (Teixeira et al., 2011, p. 6).

Baseado nesse conceito de território, os pesquisadores definiram cinco dimensões fundamentais que expressam a questão da identidade territorial, sendo: econômico-produtiva, social, política-institucional, cultural e geoambiental. (Governo do Estado de Sergipe / Secretaria de Estado de Planejamento \& Universidade Federal de Sergipe, 2007).

Figura 1. divisão Territorial do Estado de Sergipe.

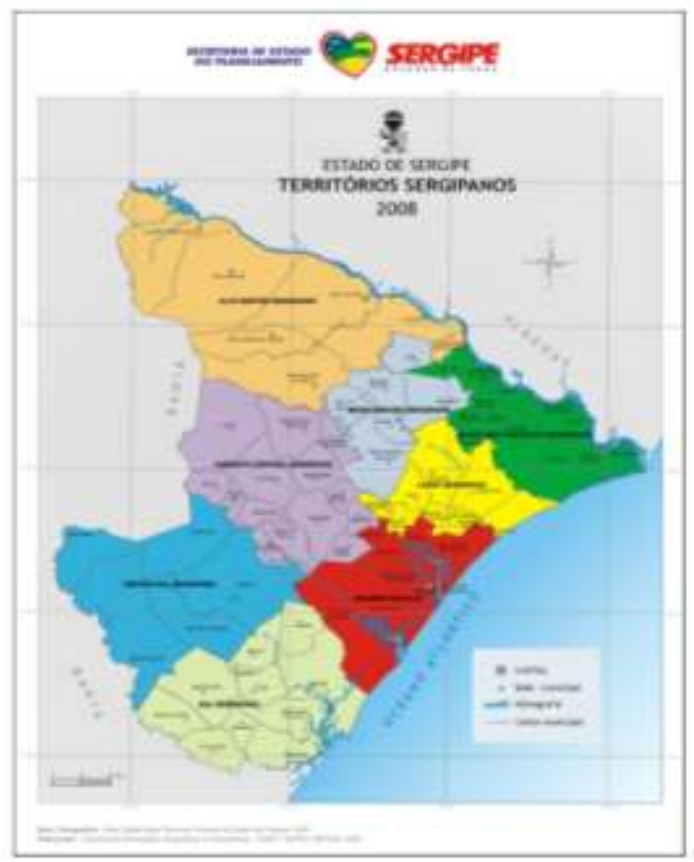

Fonte: Bases cartográficas: atlas digital sobre recursos hídricos do Estado de Sergipe, 2004. Gerência de Informações Geográficas e Cartográficas. GIGEC/SUPES/SEPLAN (2008).

Na Figura 1, é importante observar a divisão territorial do estado de Sergipe, que foram divididos em oito e foram instituídos através do Decreto n ${ }^{\circ} 24.338$, de 20 de abril de 2007.

\subsection{Cidades Pesquisadas (Amostra)}

Devido a impossibilidade temporal e orçamentária, a pesquisa só foi realizada em uma cidade de cada território (divisão territorial de Sergipe, 2007) mais a capital do Estado. Posteriormente pode-se continuar os estudos nas demais cidades. A escolha das cidades levou em consideração a cidade pólo dentro do conceito de territorialidade, que incorpora um polo macro socioeconômico em uma região específica. Nesse sentido as cidades somadas, representam aproximadamente 50\% da população sergipana e mais de $70 \%$ do Produto Interno Bruto (PIB) do Estado. 
a) Aracaju (Capital do Estado) - 623.766 habitantes;

b) Nossa Senhora do Socorro (Território da Grande Aracaju) - 174.974 habitantes;

c) Estância (Território do Sul Sergipano) - 67.953 habitantes;

d) Lagarto (Território do Centro Sul Sergipano) - 101.305 habitantes;

e) Capela (Território do Leste Sergipano) - 33.024 habitantes;

f) Itabaiana (Território do Agreste Central Sergipano) - 92.732 habitantes;

g) Propriá (Território do Baixo São Francisco Sergipano) - 29.562 habitantes;

h) Nossa Senhora das Dores (Território do Médio Sertão Sergipano) - 26.042 habitantes;

i) Nossa Senhora Da Glória (Território do Alto Sertão Sergipano) - 35.268 habitantes.

\section{Resultados da Investigação}

\subsection{Território da Grande Aracaju}

Composta por nove municípios, representa 9,98\% da superfície territorial do estado e 44,97\% da população do Estado. Os municípios que se destacam são Aracaju e Nossa Senhora do Socorro, respondendo por mais de $80 \%$ do PIB do território. Desse território foi selecionado para a pesquisa a capital Aracaju, e o município de Nossa Senhora do Socorro

\section{a) Aracaju (Capital do estado de Sergipe)}

A cidade de Aracaju, como estabelecida na metodologia, foi dividida em oito regiões, em cada região foram pesquisadas duas praças perfazendo dezesseis praças pesquisadas.

\subsubsection{Parques Pesquisados}

A pesquisa foi realizada nos três parques existentes na cidade de Aracaju: a) Parque da Cidade (Governador José Rolemberg Leite), localizado no bairro Porto D'antas; b) Parque da Sementeira (Governador Augusto Franco) localizado no bairro 13 de julho; c) Parque dos Cajueiros (Governador Antônio Carlos Valadares.) localizado no bairro Farolândia. De forma geral observa-se que os três parques pesquisados oferecem muito espaço verde e são locais privilegiados para a atividade física e lazer. Possuem módulo policial, em que pese a sensação de insegurança demonstrada por número significativo de usuários, relatos de uso de drogas e ocorrências de assaltos, fato esse que ocorre na maioria dos espaços públicos de lazer demonstrados por outras pesquisas.

Apresenta estruturas básicas para prática de atividade física, esportivas e de lazer, como campo de futebol, quadra (sem estruturas adequadas para prática do voleibol, basquetebol e handebol), espaços para caminhada, andar de bicicleta, skate, entre outros. Constata-se ausência do poder público, na aplicação de projetos e programas, na disponibilidade de profissionais de Educação Física, voltados para orientação e acompanhamento de atividades físicas, esportivas e de lazer da comunidade, seja durante a semana ou nos fins de semanas e feriados. Por fim os espaços na sua maioria são descobertos e sem iluminação.

\subsubsection{Praças Pesquisadas em Aracaju}

Foram pesquisadas um total de dezesseis praças nos oito distritos ou regiões da cidade de Aracaju, sendo duas praças por cada distrito ou região. A finalidade é que após análise e estudos desses espaços o poder público possa oferecer e qualificar ações e programas de atividades físicas esportivas e de lazer nesses polos.

A pesquisa foi realizada nas seguintes Praças: a) Praça Mariana Martins Souza, localizada no bairro 17 de Março, b) Calçadão da 13 de Julho, localizado no bairro 13 de Julho, c) Praça Dom José Tomaz, localizada no bairro Siqueira Campos, d) 
Praça do Final de linha de Ônibus, localizada no bairro Bugio, e) Praça Horácio Martins Santos, localizada no bairro Pereira Lobo, f) Orla de Atalaia, localizada no bairro Atalaia, g) Orla do Porto Dantas, localizada no bairro Porto Dantas, h) Orlinha, localizada no bairro Industrial, i) Praça da Aleste, localizada no bairro Cirurgia, j) Praça da juventude, localizada no bairro Augusto Franco, k) Praça das Mães, localizada no bairro Farolândia, l) Praça dos Beiras, localizada no bairro Aeroporto, m) Praça Franklin Delano Roosevelt, localizada no bairro América, n) Praça Maria Quitéria, localizada no bairro 18 do forte, o) Praça São Francisco de Assis, localizada no bairro Santos Dumont, p) Praça Ronaldo Calomby Barreto, localizada no bairro Novo Paraíso.

De forma geral observou-se, que apenas $42,9 \%$ das praças pesquisadas possuem módulo policial, fator que pesa quanto a sensação de segurança demonstrada pelos usuários, ficando entre baixa e média sensação de segurança e alto ou médio rumores de relatos de uso de drogas e álcool no local e a maioria desses locais possui algum tipo de estrutura danificada, inutilizada ou pichada, fato esse que ocorre na maioria dos espaços públicos de lazer.

No que se refere às estruturas para realização de atividades físicas, em geral as praças possuem: quadra multiuso, sendo de asfalto ou cimento, em sua maioria com iluminação, pista para caminhada e parquinho/playgraund em 71,4\%; já pista para andar de bicicleta e para skate/patins/rolimã existem em 57,1\%.

Quanto a presença de projetos esportivos, constata-se ausência do poder público em mais de $90 \%$ delas, seja na aplicação de projetos e programas ou na disponibilidade de profissionais de Educação Física, voltados para orientação e acompanhamento de atividades físicas, esportivas e de lazer da comunidade, seja durante a semana ou nos fins de semanas e feriados. Por fim, os espaços na sua maioria não têm cobertura, o que só possibilita o uso apenas pela manhã cedo e final da tarde. Quanto à acessibilidade, há apenas rampa para usuários de cadeira de rodas em 57\%.

\section{b) Nossa Senhora do Socorro}

Nessa cidade a investigação foi realizada nas Praças do Marcos Freire 2 e Praça do João Alves localizadas em lados opostos da cidade. Os dados pesquisados demonstraram que haviam poucos projetos e ações desenvolvidos pelo poder público municipal e poucos professores de Educação Física envolvidos com essas ações. Com relação à dificuldade de utilização dos espaços, mais da metade dos entrevistados relataram encontrar alguma dificuldade na utilização das estruturas locais, principalmente na Praça Marcos Freire 2.

Em ambas as praças não havia módulo policial e a maioria dos entrevistados relatou baixa sensação de segurança e fortes rumores de assalto, violência e uso de drogas nesses locais. No que se refere à estrutura, as praças possuem quadra multiuso, estação para exercícios; playground, local para realização de caminhada, todos com iluminação, porém descobertos. Já a estrutura para conforto do usuário, não existem banheiros, mas possuem bancos, lixeiras, iluminação e também vendedores ambulantes. Quanto à acessibilidade, há apenas rampa para cadeirantes nos dois locais avaliados.

\subsection{Capela - Território Leste Sergipano}

Composto por nove municípios representa $6,93 \%$ da superfície territorial do estado e $4,72 \%$ da população do estado, seu PIB equivale a 11,9\% do estado. A cidade de Japaratuba e Capela apresentam-se como grandes centros urbanos do território, sendo assim, a cidade de Capela foi selecionada para representar este território. A investigação foi realizada na Praça da Matriz localizada mais ao centro da cidade e Praça da Juventude situada em zona mais periférica.

Os dados pesquisados demonstraram a existência de poucos projetos e ações desenvolvidos pelo poder público municipal nesses espaços, a Praça da Juventude apresentou um índice melhor que a Praça da Matriz. Não há professores de Educação Física vinculados ao poder público para acompanhar e orientar as atividades desenvolvidas pelos usuários nesses espaços, há presença de alguns profissionais de Educação Física no local, porém com iniciativas privadas (pagas). Verifica- se 
fácil acesso às praças pela população, tendo o usuário dos locais uma média sensação de segurança e fortes rumores de assalto e uso de dragas no local. No que se refere à estrutura do local, a Praça da Matriz não oferece estrutura adequada para prática da atividade física, esportiva e de lazer. Já a Praça da Juventude apresenta uma melhor estrutura com presença de um campo de futebol, local para realização de caminhada e para andar de bicicleta, todos com iluminação, porém sem cobertura. No que se refere a estrutura para conforto do usuário, existem banheiros, bancos, lixeiras, iluminação e também vendedores ambulantes. Quanto à acessibilidade, há apenas rampa para cadeirante.

\subsection{Estância - Território Sul Sergipano}

Composto por onze municípios, que representam 14,29\% da superfície territorial do estado e 12,02\% da população do estado. Apresenta o terceiro melhor PIB entre os territórios, equivalente a $8 \%$ do estado. Desse território foi selecionada para a pesquisa a cidade de Estância, principal cidade do território, contribui com mais de 46 \% para a formação do PIB do território. A investigação foi realizada nas Praças da Walter Cardoso localizada mais ao centro da cidade e Complexo Turístico situado em zona mais periférica. Os dados pesquisados demonstraram que existem poucos projetos e ações desenvolvidos pelo poder público municipal nesses espaços, tendo o Complexo turístico um número um pouco melhor do que a Praça Walter Cardoso. Há poucos professores de Educação Física vinculados ao poder público para acompanhar e orientar as atividades desenvolvidas pelos usuários. Nos dois locais não existe módulo policial, produzindo média sensação de segurança e fortes rumores de assalto e uso de dragas no local. Quanto à estrutura, o complexo turístico possui quadra multiuso, estação para exercícios e playground com estruturas cobertas e todas iluminadas. Também é um local para caminhada e para andar de bicicleta iluminados. A Praça Walter Cardoso possui apenas o local para caminhada. Ambas possuem rampa para cadeirante, banheiros e bancos.

\subsection{Nossa Senhora da Glória - Território Alto Sertão Sergipano}

Composto por sete municípios, representa $22,37 \%$ da superfície territorial do estado e 7,08\% da população do estado. O PIB equivale a 15,7\% do estado A Cidade de Nossa Senhora da Glória e Canindé do São Francisco representam os grandes centros desse território. Desse território foi selecionada para a pesquisa a cidade de Nossa Senhora da Glória. A investigação foi realizada nas Praças da Juventude e Praça José do Fazendeiro, localizadas em zonas periféricas opostas da cidade, conforme mapa da cidade abaixo.

Os dados pesquisados demonstraram que existem poucos projetos e ações desenvolvidos pelo poder público municipal nesses espaços, e que mais da metade da população relata dificuldade em utilizar o local. Apesar de nenhum dos locais possuir módulo policial, a maioria da população relata alta sensação de segurança nesses locais. Quanto à estrutura, as praças possuem estação para exercícios, playground, local para realização de caminhada e andar de bicicleta, todos com iluminação. No que se refere ao conforto do usuário, existem banheiros, bancos, lixeiras e vendedores ambulantes. Quanto à acessibilidade, há apenas rampa para cadeirantes.

\subsection{Itabaiana Território Agreste Central Sergipano}

Composto por quatorze municípios, representa $14,25 \%$ da superfície territorial do estado e $11,24 \%$ da população do estado. Seu PIB equivale a 5,2\% do estado e possui a segunda melhor renda per capita. Desse território foi selecionada para a pesquisa a cidade de Itabaiana, principal cidade do território, com 37,5\% do total de habitantes do território é o município mais pujante da região, seu PIB representa 40,4\% da economia do território. A investigação foi realizada nas praças Fausto Cardoso mais ao centro da cidade e Praça da Juventude situada em zona mais periférica, conforme mapa da cidade abaixo.

Os dados pesquisados demonstraram que na Praça Fausto Cardoso não existem projetos e ações desenvolvidos pelo 
poder público municipal, já na Praça da Juventude a metade dos entrevistados relatou a existência de algum projeto desta natureza. Em ambos locais, mais da metade dos entrevistados relataram dificuldades em utilizar a estrutura existente. Não existe módulo policial em nenhuma das duas praças, o que explica a baixa sensação de segurança relatada e os altos rumores de assaltos e uso de drogas. No que se refere à estrutura, apenas a praça da juventude possui algum tipo de estrutura como campo de futebol, quadra multiuso, estação para exercícios, playground local para caminhada, algumas cobertas e todas iluminadas. Com relação ao conforto do usuário, em ambos locais existem banheiros, bancos, e lixeiras, iluminação e também vendedores ambulantes. Quanto à acessibilidade, há apenas rampa para cadeirante.

\subsection{Lagarto - Território do Centro Sul Sergipano}

Composto por cinco municípios, representa $16,07 \%$ da superfície territorial do estado e 10,78\% da população do estado. Apresenta o sexto maior PIB entre os territórios. Desse território foi selecionada para a pesquisa a cidade de Lagarto, principal cidade do território representando com $47,7 \%$ da economia do território. A investigação foi realizada nas Praças José Domingos Vieira e Santa Teresinha, localizadas em zonas opostas da cidade, conforme mapa da cidade abaixo.

Os dados pesquisados demonstraram que não há projetos e ações desenvolvidos pelo poder público municipal nesses espaços, bem como professores de Educação Física envolvidos com essas ações. Quanto à dificuldade de utilização do local, os usuários da Praça José Domingos relataram maiores dificuldades, enquanto que os usuários da Praça Santa Terezinha relataram baixa sensação de segurança e altos rumores de assaltos e uso de drogas. Ambos locais não possuem módulo policial. Quanto a estrutura para esporte a Praça José Domingos Vieira possui quadra multiuso. Para atividades físicas e lazer os dois espaços possuem estação para exercícios, playground, local para realização de caminhada e andar de bicicleta, todos com iluminação. Com relação ao conforto do usuário as duas praças são iluminadas, existem banheiros, bancos, lixeiras e também vendedores ambulantes. Quanto à acessibilidade, há apenas rampa para cadeirante.

\subsection{Nossa Senhora das Dores - Território do Médio Sertão Sergipano}

Composto por seis municípios, representa 7,22\% da superfície territorial do estado e 3,11\% da população do estado. O PIB do território representa 1,5\% do estado, última posição no estado. As cidades de Nossa Senhora das Dores e Aquidabã são os centros urbanos mais importantes, assim, desse território foi selecionada para a pesquisa a cidade de Nossa Senhora das Dores. A investigação foi realizada nas Praças Joel Nascimento (Praça do Jacaré) e Praça 23 de Outubro, localizadas em zonas opostas da cidade, conforme mapa da cidade abaixo.

Os dados pesquisados demonstraram que existem poucos projetos e ações desenvolvidos pelo poder público municipal, apenas na Praça Joel Nascimento, foi relatado a existência de professores de Educação Física envolvidos em ações desenvolvidas. Quanto à dificuldade de utilização das Praças, mais da metade dos entrevistados relataram encontrar alguma dificuldade na utilização das estruturas locais. Em que pese não haver módulo policial nas Praças, a sensação de segurança foi citada como média e fracos rumores de incidência de assalto e uso de drogas. Apenas a Praça 23 de Outubro possui quadra multiuso, já locais com estação para exercícios, playground e realização de caminhada foram verificados nas duas Praças, todos sem cobertura e com iluminação. No que se refere a estrutura para conforto do usuário, não existem banheiros, mas existem bancos, lixeiras, iluminação e também vendedores ambulantes. Quanto à acessibilidade, há apenas rampa para cadeirante.

\subsection{Propriá - Território do Baixo São Francisco Sergipano}

Composto por quatorze municípios representando $8,88 \%$ da superfície territorial do estado e 6,5\% da população do estado. O PIB do território equivale a 4,1\% do estado e sua renda per capita é uma das menores do estado. As cidades de 
Propriá e Neópolis representam os centros urbanos mais importantes do território, assim, desse território foi selecionada para a pesquisa a cidade de Propriá. A investigação foi realizada nas Praças da Orla e Praça de Eventos localizadas em zonas opostas da cidade, conforme mapa da cidade abaixo.

Os dados pesquisados demonstraram que na Praça da Orla, metade dos entrevistados relatou haver projetos relacionados à atividade física e profissionais de Educação Física para orientação. No entanto, na Praça de Eventos, há poucos projetos e ações desenvolvidas pelo poder público municipal. Mais da metade dos usuários relataram dificuldades quanto à utilização da estrutura local. Foi constatado que não existe módulo policial nos locais, o que condiz com a baixa sensação de segurança relatado e médio rumores de uso de drogas e de assaltos descritos pelos usuários das duas praças. No que se refere a estrutura, possuem quadra multiuso, estação para exercícios e playground com estruturas não cobertas e todas iluminadas. Em ambas as Praças, existem bancos, lixeiras, iluminação, vendedores ambulantes, porém não possuem banheiros públicos. Quanto à acessibilidade, há apenas rampa para cadeirante.

\section{Dados Estruturais Gerais, em Percentuais das Praças das Cidades Polo do Interior}

De forma geral observa-se que poucas Praças pesquisadas possuem módulo policial $(11,1 \%)$, fator que pesa muito quanto à sensação de segurança demonstrada pelos usuários, que é muito baixa, somado a médios e fortes rumores de uso de drogas, álcool e assaltos evidenciado pelos relatos presentes na maioria dos locais. A maioria desses locais possui algum tipo de estrutura danificada, inutilizada ou pichada, fato esse que ocorre na maioria dos espaços públicos de lazer demonstrados por outras pesquisas. Em poucas praças observaram projetos de atividades físico/esportivas de iniciativa do poder público. No que se refere às estruturas para realização de atividades físicas, em geral as praças possuem quadra de vôlei, futsal, basquete (construídas de asfalto / cimento) em sua maioria descobertas e possuindo iluminação. Possuem pista para caminhada e para andar de bicicleta, parquinho / playgraund, e em menor escala, pista para skate/patins/rolimã. Em geral, quanto à presença de projetos esportivos, constata-se ausência do poder público, na aplicação de projetos e programas, na disponibilidade de profissionais de Educação Física, voltados para orientação e acompanhamento de atividades físicas, esportivas e de lazer da comunidade, seja durante a semana ou nos fins de semanas e feriados.

\section{Discussão}

A realidade encontrada em ambientes diversos no estado de Sergipe muda um pouco de acordo com a localidade, conforme se pôde perceber na análise dos dados. Em locais periféricos a preocupação com a segurança é uma constante sempre encontrada. No geral, todos os parques possuem posto policial instalado, no entanto a sensação de segurança por parte dos entrevistados é média para baixa. No entanto, para o parque localizado na Zona Norte da capital sergipana, a sensação de insegurança é a maior entre os três parques estudados.

A estrutura para realização de quaisquer tipos de atividades físicas de forma geral, é satisfatória, quando se trata de atividades mais comuns, como esportes coletivos de uma forma geral, caminhadas e pedalar. Em todos os locais avaliados, é possível realizar esses tipos de atividades. Isso se reflete pela opinião dos usuários que relatam não haver dificuldades de utilização desses locais.

O que se verificou é que boa parte dos entrevistados relatam que não existem projetos orientados de atividades físicas nestes locais, e a presença de profissionais da área de Educação Física também é pouco notada. Em se tratando da estrutura relacionada ao conforto dos usuários, o que se verifica que o básico, existe, e está em condições de uso. A acessibilidade foi um ponto positivo encontrado. Entretanto, muitas melhorias com relação a outros fatores importantes como iluminação e manutenção de estruturas como pista de skate, por exemplo, são necessárias. Além disso, o poder público pode realizar a 
implementação de novos equipamentos e espaços ou renovar os antigos (Mariano \& Marcellino, 2008), para atrair mais pessoas ao local.

No que se refere às praças de Aracaju, menos de 50\% possuem módulo policial, o que é um dado muito preocupante, e quando se trata do interior, esse número é ainda menor (11\%). O aspecto do policiamento e políticas públicas de segurança são de fundamental relevância para que os indivíduos possam se sentir seguros em realizar atividades ao ar livre de forma plena. Relatos dos pesquisadores informam inclusive a dificuldade na operacionalização da pesquisa, por conta da insegurança sentida nesses locais, onde foram desferidas ameaças à integridade física dos mesmos casos esses não se retirassem do local.

De uma maneira geral, boa parte das praças analisadas possuem estrutura que propicia o acesso a atividades recreativas/ esportivas como futsal, futebol, vôlei por exemplo. No entanto, apenas uma pequena parte possui cobertura, dificultando a realização dessas atividades em determinados momentos do dia. Em contrapartida, muitos desses locais possuem iluminação, o que possibilita a prática das atividades durante a noite, pós-turno de trabalho. Áreas de convivência infantil e locais para realização de caminhadas, também são encontradas na maioria dos locais pesquisados, e as condições de conforto para os usuários, e acessibilidade se encontram em nível razoável de satisfação.

As cidades do interior não fugiram muito ao padrão do que fora visto na capital. Apesar de algumas observações quanto às condições de conservação, a maioria dos locais possui estrutura possível para realizar atividades físico-esportivas. Contudo, quando questionados sobre a existência de projetos orientados de atividade física, a maioria dos entrevistados relata não ter conhecimento. Isso indica um viés importante que distancia a possibilidade de acesso da prática de fato da atividade. $\mathrm{O}$ que se pôde perceber é que as atividades existentes, salvo alguns casos, são iniciativas privadas tais como aulas em grupos ou atividades com treinadores personalizados. Contudo, programas / projetos coletivos, para possibilitar o acesso de grandes grupos às atividades são escassos.

\section{Considerações Finais}

A atividade física é uma das melhores formas de prevenção de doenças crônico-degenerativas e também de tratamento não medicamentoso. A Organização Mundial da Saúde (OMS) recomenda 150 minutos semanais de atividade física leve ou moderada (cerca de 20 minutos por dia) ou, pelo menos, 75 minutos de atividade física de maior intensidade por semana (cerca de 10 minutos por dia). Porém aspectos econômicos e de falta de tempo com a rotina apertada de trabalho, estudo, cuidados com a casa, fazem com que muitas pessoas não tenham uma rotina de atividade física adequada.

Uma pesquisa Nacional de Saúde (PNS) mostrou que um a cada dois adultos não pratica o nível de atividade física recomendado pela OMS (Wentzel, 2018). Além disso, as pessoas sedentárias têm de 20\% a 30\% mais risco de morte por doenças crônicas, como doenças do coração e diabetes, que as pessoas que realizam ao menos 30 minutos de atividade física moderada, cinco vezes por semana.

Apesar de estar esclarecido que uma população que pratica atividade física regularmente economiza dinheiro público em cuidados com doenças, percebe-se que nos locais estudados neste estudo, apesar da facilidade de acesso ao espaço, à falta de políticas públicas de orientação em atividade física, dificultam a massificação prática para a amostra em questão.

Por fim, levando em consideração o estudo realizado nessas mesmas cidades, que relata um percentual próximo a 50\% de sedentários e apenas 30\% da população praticante atividade física de forma regular como preconizada pela OMS. Consciente das consequências dessa realidade, para saúde física e psíquica da população, torna-se fundamental a aplicação de políticas que promovam a democratização das práticas esportivas e recreativas bem como as atividades físicas voltadas para a saúde. 
Research, Society and Development, v. 11, n. 1, e17011124700, 2022

(CC BY 4.0) | ISSN 2525-3409 | DOI: http://dx.doi.org/10.33448/rsd-v11i1.24700

Convém ressaltar que, uma possível e simples solução é a implementação de programas de governo que respaldam atividades em grandes grupos, orientadas por profissionais capacitados para a atuação com treinamentos utilizando pouco ou nenhum equipamento. Dessa forma, com investimento extremamente baixo é possível agregar muitas pessoas em rotinas semanais de atividade física.

É necessário realizar mais pesquisas futuras voltadas para essa temática, aumentando a produção bibliográfica e auxiliando no desenvolvimento de políticas públicas, que consequentemente trarão bem estar para a população.

\section{Referências}

Azevedo, J. M. L. (2001). A educação como política pública. Autores associados

Barbuy, S. (1980). O espaço do encontro humano. ECE.

Bonetti, L. W. (2006). Políticas públicas por dentro. Unijí.

Caspersen, C. J., Powell, K. E., \& Christenson, G. M. (1985). Physical activity, exercise, and physical fitness: definitions and distinctions for health-related research. Public health reports, 100(2), 126.

Cheptulin, A. A (1982). dialética materialista: categorias e leis da dialética. Editora Alfa- Omega.

Demo, P. (1985). Introdução à Metodologia das Ciências. Ed.Atlas.

Dias, A. F. (2015). O ambiente escolar e o ambiente urbano como fatores intervenientes nas atividades físicas de adolescentes.

Ecker, V. D. I. (2020). O conceito de praça e a qualidade da paisagem Urbana. Revista Projetar-Projeto e Percepção do Ambiente, 5(1), 101-110.

Gomes, M. A. S. (2014). Parques urbanos, políticas públicas e sustentabilidade. Mercator (Fortaleza), 13, 79-90.

Kosik, K. (2002). Dialética do concreto. (7a ed.), Editora Paz e Terra.

Marcellino, N. C. (Org.) (2002c). Lazer \& Esporte: Políticas públicas. Autores Associados.

Marcellino, N. C. (1998). Lazer, concepções e significados. LICERE-Revista do Programa de Pós-graduação Interdisciplinar em Estudos do Lazer, 1(1).

Mariano, S. H., \& Marcellino, N. C. (2008). Equipamentos de lazer em cidades pequenas de região metropolitana. Motriz. Journal of Physical Education. UNESP, 168-178.

Minayo, M. C. S. (2004). O desafio do conhecimento: pesquisa qualitativa em saúde. (8a ed.), Hucitec.

Oliveira, A. F. S (organizador). (2019). O Esporte e lazer no estado de Sergipe: realidade e possibilidades. Tribo da Ilha.

Oliveira, A. F. S, Taffarel, C. N. Z., \& Belem, C. M. (2016). Infraestrutura Esportiva: Desenvolvimento de metodologias. Revista Brasileira de Ciências do Esporte, 36

Silva, J. V. P., Silva, D. S., \& Sampaio, T. M. V. (2018). Políticas públicas de esporte em parques e a inclusão de pessoas com deficiência. LICERE-Revista do Programa de Pós-graduação Interdisciplinar em Estudos do Lazer, 21(4), 339-358.

Teixeira, O. A., Melo, R. D., \& França, V. L. A. (2011). Estado de Sergipe: uma proposta de territorialização para o planejamento. SEPLAN Report.

Viero, V. C., \& Filho, L. C. B. (2009). Praças públicas: origem, conceitos e funções. Jornada de Pesquisa e Extensão. Anais... ULBRA. Santa Maria, 1-3.

Weineck, J. (2003). “Atividade Física e Esporte: para quê?”. Manole.

Wentzel, M. (2018). Um em cada dois brasileiros não se exercita o suficiente, diz OMS. BBC News. https://www.bbc.com/portuguese/brasil-45415691

Wilheim. J. (1976). O substantivo e o adjetivo. Perspectiva. 